\title{
PROBLEMÁTICA EDUCATIVA EN COLOMBIA. \\ EL PAPEL DEL PROFESOR, LO QUE NOS COMPETE
}

Guillermo Chona Duarte*

\begin{abstract}
This article shows an emotional vision about Colombian educational problematic. It shows the school as a place for both: Knowledge distribution and teacher formation for life in society. A position is taken about economic indicators, distribution and quality of the educational systems. It claims for teachers responsibility.
\end{abstract}

\section{PALABRAS CLAVES}

Calidad, cobertura, Colombia, conocimientos, educación, escuela, indicadores, problemática educativa, profesor.

\section{INTRODUCCIÓN}

Considero que las acciones educativas, desde la escuela, dirigidas por profesores, son una excelente estrategia que debemos tener en cuenta los colombianos para resolver los problemas que tenemos, principalmente los de la violencia.

Entiendo a la escuela como el lugar que, además de ser el espacio donde se llevan a cabo procesos de creación y distribución de conocimientos, es también formador de ciudadanos, porque en la escuela se viven hechos que son un aprendizaje de la vida en sociedad, por ejemplo: relación de los estudiantes y profesores con respecto al poder, a la participación, a la resolución de conflictos. Allí también se construyen valores para la tolerancia social, es decir, convivir con lo diferente y resolver las dificultades, las urgencias, las necesidades, los obstáculos por medio del diálogo y la negociación.

Creo que esta última visión de la escuela le permite a nuestro pueblo conocerse a si mismo, porque atenderá y entenderá su cultura y raíces; sabrá lo que quiere y para donde ir, sin simular o imitar modelos, ni vernos como marginales o tercermundistas, sino como resultado de unos hechos históricos que no nos permitieron pensarnos y que ahora vamos a superar. Convencernos de que no tenemos que ser como los otros, sino que somos diferentes. No vernos como atrasados sino que marchamos a nuestro ritmo. Creerle a

\footnotetext{
* Profesor del Departamento de Biología de la Universidad Pedagógica Nacional. Santa Fe de Bogotá, marzo de 1998
} 
Gabriel García Márquez (1994) cuando dice que se están dando las condiciones como nunca para el cambio social, y que la educación será su órgano maestro. En fin, para ser como quiso nuestro filósofo del "Viaje a Pie", Fernando González (1985), un pueblo con egoencia, como un sapo bravo. Creer en si mismo.

Yo creo que ése es el reto que tenemos los profesores. Así como también, el de incentivar en nuestros niños y jóvenes el orgullo de ser Colombianos, de educarnos para servirle a una patria acorde con nuestra cultura.

\section{LOS INDICADORES}

De manera general cuando se habla de la problemática educativa, aparecen los famosos indicadores económicos, de cobertura, de calidad entre otros; sin olvidar las políticas y los planes educativos. Aquí no vamos a ser la excepción, pero lo haré desde mi visión afectiva y no desde el análisis cuantitativo. Los porcentajes que a continuación aparecen son tomados de los documentos Misión de Ciencia Educación y Desarrollo (1994) y El Salto Educativo (1994).

- La tasa de analfabetismo en Colombia es del $13 \%$.

- El porcentaje del PIB que Colombia invierte en educación es del 2.8\%-3.07\%.

- Colombia invierte menos del $0.4 \%$ en investigación.

- Colombia participa en el porcentaje mundial de científicos con un $0.01 \%$.

Estos datos no nos dicen nada si no los comparamos Por ejemplo que en la mayora de los países desarrollados el analfabetismo fue erradicado, que en países como en Canada el porcentaje del PIB invertido en educación es del 7.4\%. que los países desarrollados invierten en algunos casos, más del $4 \%$ del PIB en investigación y que participan con el $94 \%$ de los científicos existentes en el mundo.

Por otra parte, de 100 niños que ingresan al sistema educativo, a primero de primaria solo 60 terminan quinto grado y 30 culminan la educación básica (noveno grado). Anualmente egresan de la secundaria 295000 jóvenes, de los cuales sólo el 25\% pasa al nivel superior.

En aspectos de calidad, en Colombia se reciben en promedio 680 horas de clase al año, contra 1.100 en Estados Unidos, 1.200 en Corea, 1.300 en Europa, y 1.500 en Japón. La jornada real escolar es en promedio de 3,5 horas diarias. Para el trabajo escolar en los primeros años, a los profesores que los atienden, se les permite el más bajo nivel preparatorio, la normal.

Pero el asunto tampoco puede quedar así, aquí es donde son importantes las misiones y los estudios de los indicadores (Misión de ciencia, educación y desarrollo, El salto educativo, La calidad de la educación). Es muy triste que de cien colombianos, trece no sepan leer ni escribir, hoy cuando nuestra evolución cultural nos exige la lectura del símbolo, ellos están ya perdiéndose parte de nuestro mundo construido y sin tener la posibilidad de comunicarse de manera escrita. Así, Colombia pierde la posibilidad de esas trece potencialidades interpretativas del mundo. 
También es trágico que setenta de cien colombianos no culminen la formación básica, pero tenebroso seria, que cien colombianos terminen la básica donde está primando una pedagogía de la violencia, en ese caso es prudente que el ciento por ciento no la culmine.

Son varios los informes que nos hablan acerca de la puesta en práctica de la pedagogía de la violencia, el regaño como pedagogía, la humillación como pedagogía, el castigo como pedagogía, y otra que nos puede parecer rara, pero es la más practicada, la violencia del conocimiento autoritario; violencia, que como dice Rodrigo Parra, está... "implícita en la actitud del profesor que escamotea al alumno la incertidumbre que conlleva la aventura del descubrir. El profesor realiza este escamoteo por medio del ofrecimiento de los resultados del conocimiento en forma de información y en ese caso suplanta la búsqueda, los caminos de la búsqueda" ${ }^{1}$. Así, nuestros niños y jóvenes en la mayoría de los casos no han podido poner en cuestión sus creencias, es decir, la forma intuitiva como fue armado, en parte, su mundo.

Hoy sabemos que todos nosotros, de acuerdo con el ambiente cultural en que vivimos hacemos interpretaciones del mundo, pero buena parte de esas interpretaciones no son coherentes con la interpretación científica, y la cultura científica se adquiere a un gran precio; ella no es producto del azar, hay que hacer un inteligente y seductor trabajo para obtenerla. Si bien, todos estamos dotados de lo que la hace posible: el lenguaje, la imaginación, la simbolización, la metáfora, la voluntad de saber y de poder, esto solo no hace posible que cualquiera llegue a ella. La cultura científica exige preparación de los sentidos, en la idea de ver o que no existe, saborear lo que retiene gusto olfatear lo que no tiene olor, oírlo que no vibra, tocarlo intangible o insustancial, en fin ampliar el espectro de a sensibilidad. Ahí es donde actuamos nosotros os profesores.

A niños y jóvenes prácticamente se les obligó a creer que la tierra es redonda, que la célula es la unidad estructural, funcional y de origen de todos los seres vivos, que todos los cuerpos en el vacío caen al mismo tiempo y que menos por menos da más: por mencionar algunos casos, acerca de la forma como fue atropellada la construcción de su mundo.

La enseñanza aún se dirige tercamente con un énfasis a la adquisición de conocimientos, entiéndase información. El trabajo de los cursos todavía se realiza obedeciendo a una lógica que ha sido decantada del desarrollo disciplinar y académico, pero no del desarrollo armónico natural del niño y del joven. Por ejemplo. la iniciación a la química debe empezar por el átomo, precisamente por lo más complejo, que no se conduele en nada de la condición del niño y del joven, porque entender el átomo tiene que ver con una concepción discontinuista del mundo y posiblemente eso sea un a priori Kantiano, pero entenderlo desde Schrôdinger, Heisemberg, Bohr o Brogli ya es distinto; para eso se necesita haber vivido más de quince años y haberlos estudiado con mucho detenimiento y me parece que un jovencito de diez años lo aprenderá como cliché y además le creará el obstáculo de la "ilusión de saber" y perderá el encanto de la pregunta.

La posibilidad de trabajar en la transformación del sistema cognitivo en niños y jóvenes, en la idea de que el aprendizaje también es transformación y no captación de algo independiente de nosotros, parece aún un imposible. La mayoría de las investigaciones que auscultan ¿qué queda de aprendizaje significativo en los jóvenes después de graduados? Concluyen que mucho de lo aprendido, no les sirve en su vida

\footnotetext{
${ }^{1}$ PARRAS . Rodrigo. 1992. Introducción. La escuela violenta Ed Tercer Mundo Bogotá Pág. 17 
cotidiana. Coexisten después dos mundos en las personas, uno academizado - escolar y otro el de la vida real. En Colombia la ciencia aún es mito. La cultura científica todavía no se ha arraigado.

Resulta paradójico cuando nuestros estudiantes nos exigen ese ofrecimiento de información en las clases y catalogan de mal profesor al que no lo hace. ¿Será que ya está introyectada la violencia?

Pero volvamos a lo que inició este aparte. En una sociedad violenta, la escuela debe constituirse en una cultura alternativa a la violencia social, una escuela de paz, de vida democrática.

Culminemos este aspecto de los indicadores comentando, que los países desarrollados pueden hacer esas grandes inversiones, primero porque ellos se han dado cuenta del papel que juega la educación, principalmente en los aspectos ideológicos y porque son conscientes que así se perpetuarán en la dominación.

\section{LA SITUACIÓN DEL MAESTRO}

Para ninguno de nosotros como docentes, es desconocida la función que tenemos como administradores del currículo, entiéndase dispensadores de contenidos de una disciplina, controladores de tiempos y espacios, juzgadores de la memorización de contenidos y de conductas disidentes, a que fue reducida la acción del profesor por obra y gracia de una revolución pedagógica, el tecnologismo educativo y sus ciencias de la educación. Esta revolución funcionó con la consigna de la realización de programas a prueba de profesores, un ejemplo es la instrucción programada.

Consecuencia de ello fue la organización, y aquí ya entramos en aspectos de política, de una estructura educativa que fija científicamente el currículo, en aras de aplicar un modelo metodológico muy exitoso de dominio y de utilización de la naturaleza como lo es el positivismo, en educación. Dicho currículo está lógicamente alejado de nuestra realidad cultural, porque lo hacen expertos que han usufructuado la cultura universal, pero no la nuestra. Ellos dicen qué enseñar, cuándo, cómo y dónde; el a quién y el por qué generalmente queda implícito. El profesor entonces se acostumbró a esperar las instrucciones y por eso hoy tenemos tantas dificultades para hacer los Proyectos Educativos Institucionales y la evaluación, además de las resistencias para aceptar el cogobierno escolar.

Por otra parte también sabemos la forma tan circunstancial y azarosa como se forman nuestros profesionales educadores, los licenciados.

En Colombia no existía una política educativa que se enmarcara en un propósito nacional y siempre estuvo supeditada a la coyuntura de unas políticas partidistas, de un cuatrienio presidencial o a los caprichos de los múltiples ministros de educación. Hoy contamos con una Constitución que la define como un servicio público, determina responsabilidades y obligaciones. Leyes que reglamentan su organización, su estructura, el gobierno, la autonomía, la planeación, planes, proyectos, evaluación y control.

Bueno, ésta es otra posibilidad que se nos ofrece a los profesores para realizar un trabajo inteligente acorde con nuestra realidad, de la que quiero decir algunas cosas. 
Realidad sentida, aquella que vivimos a diario los maestros en el aula, en la institución, en nuestros hogares; es decir en lo afectivo, lo sensible, en el emocionar, donde los otros surgen; nuestros compañeros, nuestros alumnos, los directivos, los padres. Es en ellos que la educación y la escuela toman su carácter humano. Es ahí, donde yo creo que sin necesidad de grandes planes los profesores, desde ya, podemos cambiar.

Empecemos por reconocer el desconocimiento que tenemos los profesores de nuestra cultura, ¿quiénes somos?, ¿cómo obramos?, ¿cómo conocemos? Gabriel García Márquez, en el informe de la Misión de Ciencia, Educación y Desarrollo. Colombia al filo de la Oportunidad, nos dice: “... Dos dones naturales nos han ayudado a sortear ese sino funesto, a suplir los vacíos de nuestra condición cultural y social, y a buscar a tientas nuestra identidad. Uno, es el don de la creatividad, expresión superior de la inteligencia humana. El otro, es una arrasadora determinación de ascenso personal. Ambos, ayudados por una astucia casi sobrenatural y tan útil para el bien, como para el mal... Tal vez de esos talentos precolombinos nos viene también una plasticidad extraordinaria para asimilarnos con rapidez a cualquier medio y aprender sin dolor los oficios más disímiles: fakires en la India, camelleros en el Sahara o maestro de inglés en Nueva York"2. De igual manera Gabriel García Márquez, en otro documento, Un Manual para ser Niño", dice que lo escribe, para que los niños se atrevan a defenderse de los adultos en el aprendizaje de las artes y las letras.

Pensemos por un momento lo que pasarla si los profesores tuviéramos en cuenta esos dones que nos plantea Gabriel García Márquez tienen nuestras gentes. Yo les cuento que me he sorprendido, cuando voy a ver a mis alumnos realizando práctica docente y observo a un jovencito colgado de unos walkman, peloteando un balón y molestando a su vecino, y para llamarle la atención le pregunto que dijo el profesor, y él, muy tranquilo me recita con pelos y señales lo que últimamente ha dicho el practicante. Estas son habilidades que buena parte de nuestros niños y niñas tienen y que poco a poco se las vamos quitando para habituarías a los cánones de la atención. Hoy un jovencito observa cinco canales de T.V. al tiempo, gracias a la magia del control remoto, y puede dar razón de lo que está sucediendo en cada canal, pero nosotros somos monotemáticos cuando trabajamos una clase, imagínense lo aburrido que puede resultar para un niño o niña que tiene esas habilidades.

Los maestros debemos aprender de esas habilidades de los niños y de los jóvenes de hacer varias cosas al tiempo y mantener la atención; por ello insisto, que debemos conocer de la condición del joven y del niño, más que enseñarles algo, ayudémosles a potenciar esas habilidades, ahí si, no nos pararía nadie en lo científico, económico e industrial. Ahí si, tendría sentido lo propuesto por el doctor Llinás, en la Misión de Ciencia, Educación y Desarrollo.

Los profesores debemos documentar nuestra realidad educativa, escribir describiendo todo aquello que sucede en el aula, en la institución; convirtamos cada una de nuestras clases en una acción investigativa. Así construiremos el saber propio de nuestra pedagogía. Prestémosle atención, a Humberto Maturana, cuando habla que en la relación materno-infantil aprendimos a respetar, aprendimos a colaborar, aprendimos a participar,

${ }^{2}$ GARCÍA M Gabriel. 1994 Por un país al alcance de los niños. Misión de Ciencia, Educación y Desarrollo Pág 15. 
aprendimos a conversar, a no resolver nuestras discrepancias en la mutua negación. Tomemos algo de esto para nuestra acción como formadores.

En el informe Atlántida (1995), un buen trabajo etnográfico sobre la juventud Colombiana y sus relaciones con la escuela, se muestran realidades muy dolorosas para nosotros los profesores, acostumbrados a ciertos esquematismos, acerca de cómo los jóvenes ven la escuela y a los adultas: por ejemplo, para los jóvenes es muy claro que ellos van a la escuela no a aprender (y nosotros estamos convencidos de que a eso es que van) sino a encontrarse con su igual, a hacer vida social; que les mienten a los adultos porque si les dicen lo que sienten y las verdades, salen perdiendo. Nos estamos engañando mutuamente.

En definitiva estamos desaprovechando unas condiciones casi innatas de nuestros niños y jóvenes, por aplicar metodologías obsoletas de enseñanza.

Sobre esto último quiero transcribirles algo de un libro de Nicolás Buenaventura (1995), que me ha llamado muchísimo la atención y que tiene que ver con lo que estoy comentando En un capitulo. El Tiempo Total dice. En las vaquerías de los llanos orientales colombianos ocurre a menudo que por causa de un trueno intempestivo o un disparo a destiempo o a veces sólo por un mal grito, la tropa de ganado se asusta y se alebresta y echa a correr en desbandada Entonces allí no hay nada que hacer La cuadrilla de vaqueros a caballo sabe que debe esperar, que no puede tratar de atravesárseles a las bestias desbocadas en la huida, que tiene que abrirse y dejarlas que huyan

Pero, ¿cómo rescatar el hato?, ¿cómo recuperarlo? Es en ese momento cuando los llaneros echan mano de un recurso que nosotros no imaginamos: ellos cantan entonces, silban y cantan tonadas de vaqueros Persiguen a todo correr las partidas de ganado entonando joropos o galerones. $Y$ de esta manera logran el objetivo porque de allí en adelante todo consiste en ir acortando el paso para que los animales que van en la punta o la delantera no alcancen a oír bien y empiecen a perder la tonada.

Aquí el trabajo se convierte en juego, el hombre juega con el toro, como el que danza con una pareja. El hombre sabe que no hay lazo que ataje a la tropa desbocada mejor que un joropo bien cantado. Porque 108 animales se azaran al perder la tonada y empiezan a torcer el cuello y a parar las orejas, con lo cual van frenando y enredando la escapada hasta que se aquietan y se arremolinan, En ese momento se reinicia la faena, o sea el trabajo rutinario de la vaquería ${ }^{3}$.

Utilizo el ejemplo no en la idea de atajar a nuestros niños y jóvenes en sus creatividades, sino para rescatar esa capacidad de los llaneros de ser unos observadores hábiles y de encontrar metodologías en la faena donde al final resultan es divirtiéndose. Yo creo que los maestros debemos aprender de los llaneros, oigan bien, silbar, cantar y danzar. Si el ejercicio de la docencia por sí es bueno, ahora imaginémoslo además con estas posibilidades. Tal vez, así, resolvamos de verdad, parte de la problemática educativa Colombiana.

\footnotetext{
${ }^{3}$ BUENAVENTURA Nicolás. 1995. La importancia de hablar mierda. O los hilos invisibles del tejido social Ed Magisterio Santafé de Bogotá Págs 26-27
} 


\section{BIBLIOGRAFÍA}

ALZATE MEDINA y otros. 1995 La cultura fracturada. Ensayos sobre la adolescencia colombiana. Tomo I. En: Proyecto Atlántida. Estudio sobre el adolescente escolar en Colombia. FES-COLCIENCIAS. TM Editores. Santafé de Bogotá.

BUENAVENTURA, Nicolás. 1995. La importancia de hablar mierda. O los hilos invisibles del tejido social. Magisterio Santafé de Bogotá.

CONPES-MEN. 1994. El salto educativo. Santafé de Bogotá.

GARCÍA MÁRQUEZ, Gabriel. 1994. La proclama. Por un país al alcance de los niños. Misión de Ciencia, Educación y Desarrollo. Santafé de Bogotá.

GONZÁLEZ, Fernando. 1985. Viaje a pie. Oveja Negra. Bogotá.

MATURANA, Humberto. (sf). La democracia es una obra de arte. Magisterio. Santafé de Bogotá.

MEN. 1996. Plan Decenal de Educación 1996-2005, Santafé de Bogotá.

MISIÓN DE CIENCIA, EDUCACIÓN Y DESARROLLO. 1994. Santafé de Bogotá.

PARRA, GONZÁLEZ, MORITZ, BLANDÓN, y BUSTAMANTE, 1992. La escuela violenta Tercer Mundo. Santafé de Bogotá. 